\title{
A Finite Element Approach to the Möhr- Coulomb and Kupfer-Hilsdorf-Rusch Concrete Failure Criteria in Tension
}

\author{
A. L. Han, Sukamta, and B. R. Indriyantho
}

\begin{abstract}
Over the years, the failure envelope of plain concrete has been studied and constructed by various researchers. Since concrete is a non-homogeneous material, its behavior under bi-axial stresses is not as straight forward as steel. Also, the assumption that concrete exhibits an isotropic behavior under loading is not completely true since the failure mode due to tension and compression differs significantly. This research work looked into the correctness of the two most known failure criteria; the Möhr-Coulomb (MC) and the KupferHilsdorf-Rusch (KHR) envelope. In reaching the goal, a Finite Element Model (FEM) was constructed, and a plain concrete beam subjected to flexure was run through the program for a range of concrete compressions strengths. To validate the FEM program, the resulting load-displacement curves were calibrated to experimentally tested specimens. The load-displacement response and the stress-strain behavior at the beam's center-line up till failure, was recorded for analyze purposes. This research work was conducted at the Structural and Material Laboratory, Diponegoro University in Semarang, Indonesia.
\end{abstract}

Index Terms - Finite Element Model, failure criteria, bi-axial stresses.

\section{INTRODUCTION}

A S early as in 1876 the failure envelope of plain concrete was established by Rankine, and soon perfected by Möhr-Coulomb in the 1900's. The later was a generalized version of the Tresca criterion. More complete formulations were further developed by DruckerPrager in 1952, and in the 1969 Kupfer-Hilsdorf-Rusch introduced the failure envelope which includes the confinement effect of concrete in bi-axial compression. This criteria was later expanded by many researchers, and used in its elaborated form by a number of codes and standards.

Although the research leading to the formulation of these failure criteria were a result of extensive studies, it is up till now still an open question which criteria is most suitable for representing the actual tensile behavior of a concrete member,

Manuscript received May 22, 2014.

A. L. Han is with the Civil Engineering Department, Diponegoro University, Semarang, Indonesia (e-mail: ayliehan@indosat.net.id).

Sukamta is with the Structural and Material Laboratory, Diponegoro University, Semarang, Indonesia (e-mail: kamt_id@yahoo.com).

B. R. Indriyantho is with the Master Program in Civil Engineering, Diponegoro University, Semarang, Indonesia (corresponding author to provide e-mail: bobbyrio77@yahoo.com). for a variety of cylindrical compression strengths. In this study attempts has been made to evaluate the degree of correctness of the two most widely used failure criteria, the KupferHilsdorf-Rusch's [1] failure envelope and the Möhr-Coulomb failure criteria [2], [3]. The research method chosen for this work was by constructing a Finite Element Model (FEM) program, written in the VB language (Microsoft Visual Basic) that incorporated the mathematical formulations of the two failure criteria.

To ensure that the developed FEM program was correct and reliable, complimentary experimental test were used as calibrating tool to validate the outcome of the program. Identical specimens were casted in the laboratory, and tested under the same conditions and loading details as the FEM. The material properties such as the concrete cylindrical compression strength $f_{c m}$, the tensile strength $f_{t m}$ and the Poisson's ratio $u$ were obtained experimentally as well. These data functioned as input for the FEM program. Beside the experimental test results, data from other researchers were also accessed to ensure that the FEM program could cover a broad range of compression strengths. The comparison between the two failure envelopes is presented in Fig. 1.

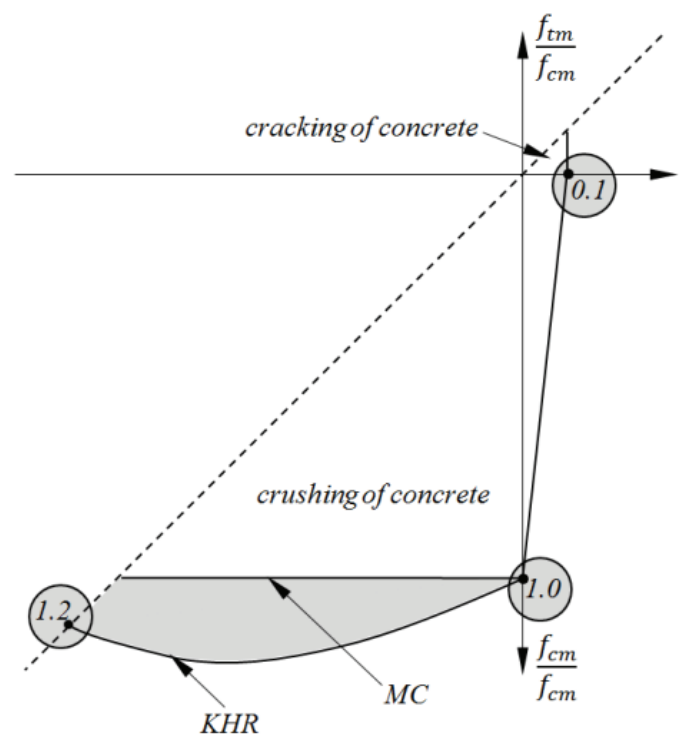

Fig. 1. MC and KHR failure envelope in the deviatoric plane 


\section{CONCRETE FAILURE CRITERIA}

\section{A. The Möhr-Coulomb Criteria}

The Möhr-Coulomb (MC) failure criteria is a mathematical model described as a set of two linear equations, forming the field surface of brittle material in terms of their normal $\left(\sigma_{n}\right)$ and shear stress $\left(\tau^{\prime}\right)$. The formulation of the $\mathrm{MC}$ failure criteria is as following.

$$
\left|\tau^{\prime}\right|=C^{\prime}+\sigma_{n} \tan \phi
$$

The $C^{\prime}$ coefficient stands for cohesion, while the $\phi$ represents the angel of internal friction. The numerical formulation defines the critical combination of $\tau^{\prime}$ and $\sigma_{n}$ that causes failure of an element [2], [3]. In the absence of the cohesion, only a bi-axial compression state exist, while a nonzero $C$ ' will expand the failure modes to bi-axial compression, bi-axial tension and compression-tension. Failure of a Gauss point can be evaluated based on the shear $\tau^{\prime}$ and normal stresses $\sigma_{n}$, or as a function of the principal stresses $\sigma_{1}$ and $\sigma_{2}$.

\section{B. Kupfer-Hilsdorf-Rusch Criteria}

The Kupfer-Hilsdorf-Rusch (KHR) failure criteria was developed as an envelope that forms the boundaries of concrete failure in the two-dimensional deviatoric plane. The KHR criterion differs from the MC formulation solemnly in the bi-axial compression zone. Whiles the MC mandates the boundaries only to the cylindrical compression strength $f_{c m}$, the KHR envelope includes the effect of confinement due to the bi-axial stress state [1]. The both the failure envelopes were developed on the assumption of a negative sign for compression stresses, and a positive for tension. Fig. 1 demonstrates the dissimilarity between the MC and the KHR failure envelope.

The first quadrant explains the bi-axial tension condition. The detailed KHR envelope expresses a slight rounding at the upper most borders, which is negligible. Elements falling under this criterion, fail by cracking of the concrete perpendicular to the direction of the major principal tensile stress. The remaining direction, i.e. perpendicular to the minor principal tensile stress, will still be able to contribute an amount of stiffness to the system. However, when an isotropic approach is chosen in the analysis, this contribution is not accommodated for. The KHR in its simplified, linear form is exactly similar to the MC criterion. The mathematical expression for this zone is written as:

$$
\sigma_{1}-f_{t m} \leq 0
$$

$$
\text { For } \sigma_{1} \geq \sigma_{2} \text { and } \sigma_{1}>0, \sigma_{2}>0
$$

The second and forth quadrants represent the tensioncompression mode. This mode is actually the most sensitive, and most probably leads to the initial cracking of the material. The failure behavior is characterized by a combination of initial cracking, followed by crushing of the element under the compression stress. The stress levels for which failure occur are far below the concrete cylindrical compression strength $f_{c m}$ and tensile strength $f_{t m}$ due to the distinctive nature of the curve. The numerical expression is written as:

$$
\begin{gathered}
\sigma_{1}+\left[\frac{f_{t m}}{f_{c m}}\right] \sigma_{2}-f_{t m} \leq 0 \\
\text { For } \sigma_{1}>0 \text { and } \sigma_{2}<0
\end{gathered}
$$

The third quadrant requires two different sets of formulas, since the KHR criterion includes a $20 \%$ increase in compression strength due to the confinement effect. The envelope has an ellipse formulation and follows a second order expression. The European Code through the FIB-CEB has adopted this envelope for their standard [4], [5]. The MC criterion follows the formulation as:

$$
\begin{gathered}
\sigma_{1}-f_{c m} \leq 0 \\
\text { For } \sigma_{1} \leq \sigma_{2} \text { and } \sigma_{1}<0, \sigma_{2}<0
\end{gathered}
$$

\section{MATERIAL BEHAVIOR, ISOTROPY VERSUS ORTHOTROPY}

The material was considered orthotropic, since previous studies [6]-[8] showed that the assumption of an uniform modulus of elasticity $E$ representing both the material stiffness in the $\sigma_{1}$ and $\sigma_{2}$ direction, lead to a significant error in the FEM output. The methodology approached in programming was to update the material stiffness as a function of the incremental stress and strain levels. The tangent stiffness was chosen in favor of the secant and chord stiffness, since the decrease in the material stiffness was better represented by this method.

When in bi-axial tension, the degree of strains $\varepsilon_{1}$ and $\varepsilon_{2}$ determine the stiffness $E_{1}$ and $E_{2}$. Upon reaching the boundaries of the envelope, a crack occurs, and the stiffness in this direction drops to zero. The stiffness in the direction of the minor stress however, remains in the formulation of the material matrix. Since the tangent stiffness was chosen, the material matrix as proposed by Chen and Saleeb [6] was used. A similar procedure was conducted for the stiffness adjustments in the bi-axial compression zone, except that when reaching the periphery of the envelope, both the stiffness $E_{1}$ and $E_{2}$ were set to zero. Crushing of concrete is an integral phenomenon, and upon it, no stiffness is retained within the element.

The tension-compression zone basically followed the same pattern as the bi-axial tension mode, except that the manifestation of cracks in tension induces a decrease in compression stiffness. The theory as outlined by Vecchio and Collins [7] was used to generate the modification of the compression stiffness.

\section{PRogram Validation And Results}

To study the significance of the MC criteria as compared to the KHR envelope, a program in the Visual Basic language was written. The algorithms were developed based on the Finite Element Analysis (FEA) of a plain concrete beam in pure flexure. The program produced the load-displacement response of the beam under a constant, incremental monotonic load. The load-displacement curves were further calibrated to experimentally tested beams with the exact same material 
properties, dimensions and loading conditions. This research work thus consists of two major items, the construction of the FEM program, and the experimental study for validation purposes. The overview of the research work is presented in Fig. 2.

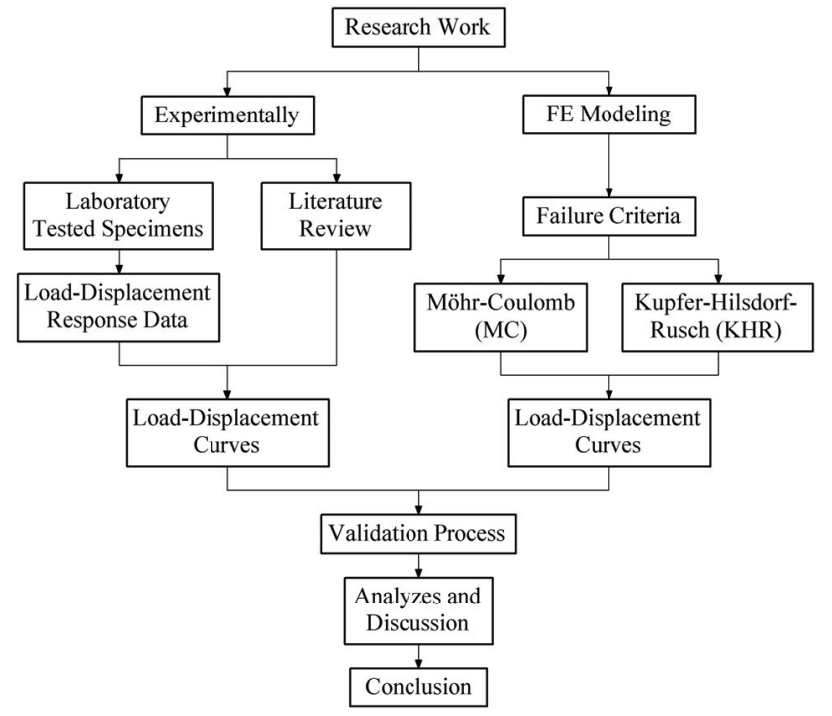

Fig. 2. Outline of research work

\section{A. Experimental Work}

The laboratory tested specimens functioned as calibrating tool to the program. The beam was a plain concrete specimen sized $100 \times 176 \mathrm{~mm}$ with a length of 2 meters. The beam was loaded longitudinally with a two-point loading system, 640 $\mathrm{mm}$ apart to ensure a pure bending behavior. The beam was simply supported, and supports were located at a distance of $40 \mathrm{~mm}$ from the beam's end [8], [9]. Two identical specimens were prepared and tested. The experimental set up is shown in Fig. 3.

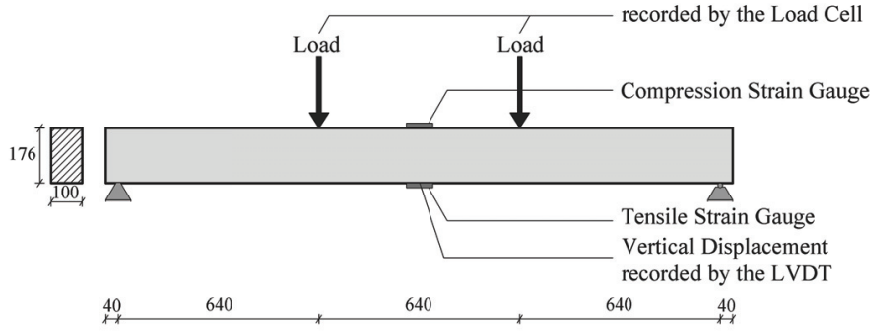

Fig. 3. Experimental beam set-up

The material properties such as the compression and tension strength, the Poisson's ratio and Young's modulus were obtained from cylindrical specimens size 150 by $300 \mathrm{~mm}$. Six cylinders were tested at the age of 28 days. The measuring equipment's were a load cell type CLC-500 kNA with a capacity of $500 \mathrm{kN}$ and a sensitivity of $1.5 \mathrm{mv} / \mathrm{v}$, and three LVDT's type CDP-25M having a rated output of $10000 \times 10^{-6}$ strain and a sensitivity of $2000 \times 10^{-6}$ strain $/ \mathrm{mm}$. To control the restraining effect between the compression apparatus' loading plates and the specimens, a double layer of $100 \mu \mathrm{m}$ Teflon (PFTE or polytetrafluorethylene) separated with a layer of bearing greased, was placed on the top and bottom of the cylinders. The loading rate was set to $0.25 \mathrm{MPa} / \mathrm{s}$. The concrete was recorded having a cylindrical compression strength of $38 \mathrm{MPa}$, combined with a Poisson's ratio of 0.2 . The stress-strain relationship was in accordance to the FIB Code [5].

Apart from the experimental test data, data from other researchers on similar specimens were accessed to enrich the validation data base, and to serve as information to the correctness of the program's output [10], [11]. Although the later dialed with recycled aggregates, the analyses results were of high value to evaluate the FEM program since the material properties could be implemented into the FEM program.

\section{B. Finite Element Modeling}

The developed FEM program was a two-dimension nonlinear material model, analyzed as a plain stress element. The isoparametric quadrilateral element with two by two Gauss points was chosen. Each Gauss-point was classified based on the characteristics of principal stresses within the failure envelope. An increase in stress resulted in a decrease of the material stiffness modulus $E_{1}$ and $E_{2}$. This in turn, descended the stiffness of the beam. A Gauss point was considered a failure when the bi-axial stress combination at this point exceeded the boundary of the envelope. In modeling, this was achieved by setting a very small value, approaching zero, for $E$. However, the corresponding nodes of this element remained in the structural matrix, since the other surrounding Gauss points still contributed to the stiffness matrix of that specific element. Upon load increase, the number of failed Gauss points accumulated. The operation of the structural stiffness matrix, however, was manageable due to the assignment of a very small value for the stiffness modulus at failure; ensuring a non-zero determinant at all times [12].

The program consists of one main program and a number of sub-routines. The main program basically generated the load-displacement behavior and recorded the balanced points at each loading stage. All material properties, beam dimensions and number of elements in the vertical en horizontal direction were inputted into the main screen. The subroutines executed the matrix operations, the material stiffness adjustments and the boundaries of the MC and KHR failure envelope. Fig. 4 shows a graphical presentation of the output window.

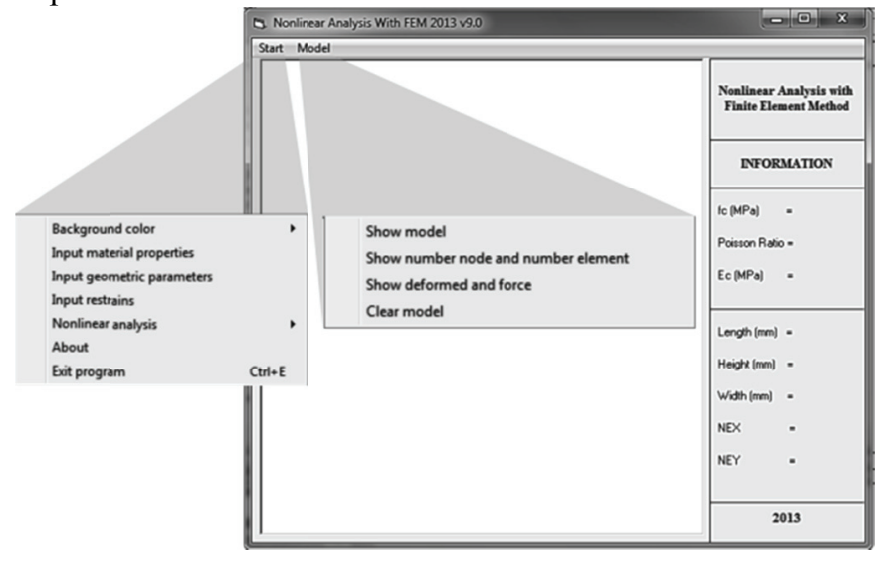

Fig. 4. FEM program main-window 
The program run the required algorithms to produce the load-displacement response at the assigned loading level. Iterations were conducted to converge the external load to the internal forces. The FEM program recorded the converged points and stored these data in the computer's memory. The iterations were performed by the Newton-Raphson method. The calculated data can be exported to any spreadsheet.

\section{Load-displacement Response}

The failed Gauss point propagation gave a picture of the element state, as a function of the loading progress. When all four Gauss points within a particular element exceeded the failure envelope, the element had failed. This element theoretically left a physically gap in the structure. With finer meshing, the failure progress of Gauss points and elements could be observed closely. Fig. 5 represents the data as produced by the FEM program, with their corresponding experimentally obtained points.

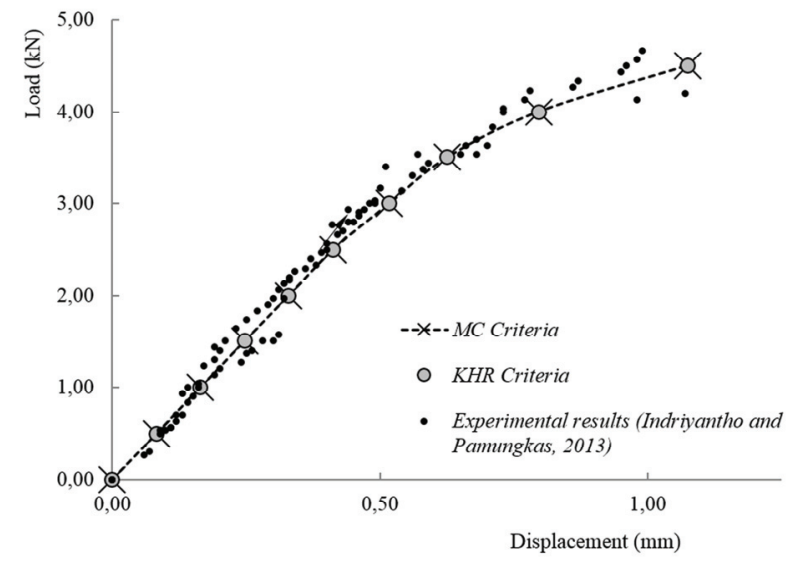

Fig. 5. Load-displacement response validation

The program was proven to function well, the experimentally tested specimen's data were scattered in the vicinity of the predicted load-displacement curve. The program resulted in a slightly conventional outcome at higher stress levels. Since the FEM program was proven to be accurate, concrete strengths ranging from $10 \mathrm{MPa}$ to $100 \mathrm{MPa}$ were run through the program, and the ultimate load was recorded (Fig. 6).

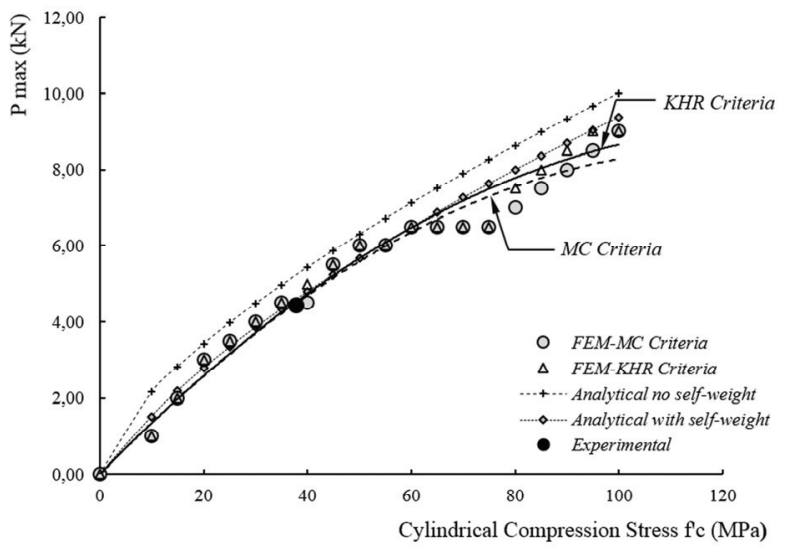

Fig. 6. MC and KHR criteria comparison
In combination to the ultimate load as predicted by the program, the ultimate load was also determined analytically, based on structural mechanics theories. Two sets of data were obtained, one set including, and another omitting the selfweight of the beam. In programming, the self-weight was not accounted for. The comparison between the MC and KHR to the predicted load was plot against the analytical results.

\section{Stress-strain Response}

The FEM program also recorded the nodal stresses and strains for every balanced point. The response of the stress and strain levels at the center of the beam were evaluated by plotting against the nodal coordinates. Figure 7 demonstrates the horizontal strains for a loading of respectively $0.5 \mathrm{kN}$ and $4.5 \mathrm{kN}$ at failure. The stress levels in the horizontal direction (global X-X axes) were outlined in a similar matter and are shown in Fig. 8. The outcome of the MC and KHR failure criteria resulted in the exact same values for both stress and strain.

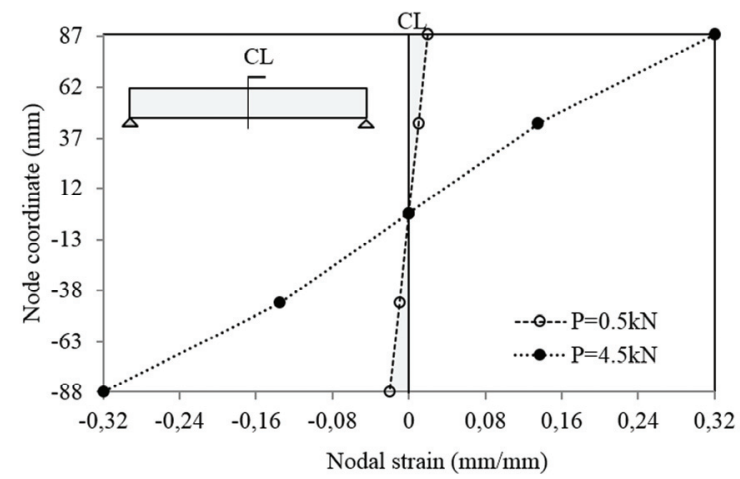

Fig. 7. Nodal strains in the $\mathrm{X}-\mathrm{X}$ direction

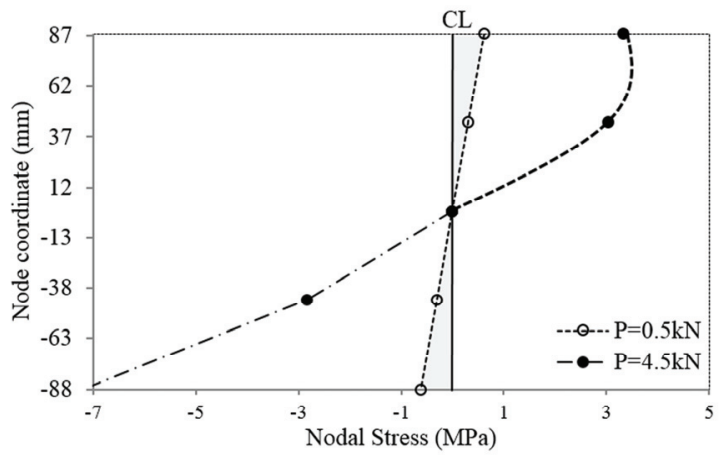

Fig. 8. Nodal stresses in the $\mathrm{X}-\mathrm{X}$ direction

\section{DISCUSSION}

It was demonstrated that the excluding of self-weight in the FEM resulted in a $10 \%$ to $20 \%$ overestimation of the ultimate load carrying capacity. This is explained by the fact that the self-weight of concrete is relatively high. When the selfweight was accounted for by the FE program, the resulting load-displacement response closely approached the curves 
obtained from the laboratory tested specimen.

As for the MC and KHR curve comparison, the outcome of the ultimate load carrying capacity of both failure envelopes were identical for a concrete compression strength $f_{c m}$ lower than $75 \mathrm{MPa}$. Beyond this strength, the KHR failure envelope predicted a higher ultimate load when compared to the $\mathrm{MC}$ criteria. Irregularities in the outcome of the FEM program were detected at readings of $f_{c m}=60 \mathrm{MPa}$. An increase in concrete strength resulted in an exact same predicted ultimate load. The program was designed with a constant load increment that probably lead to this less correct outcome.

The strain response at a $10 \%$ of the ultimate load was linear, and symmetric with respect to the neutral axes. At ultimate, the strain diagram showed a slight discontinuity. In reality, failed elements will have a zero material stiffness and leave a physical gap in the structure. The program was designed by mandating a very small value for a failed Gauss point, thus the element will never fail. As a consequence, the resulted strain at cracking will deviate from the linear strain pattern as proposed by Bernoulli's theorem.

Observing the stress behavior at the center of the beam it was shown that at low loading levels, a linear stress pattern occurs. The top fibers are in extreme compression, while the bottom fibers are in tension. The stress at the neutral axes was zero. Upon load increase, the stresses at nodal points became non-linear. At failure the stress diagram in tension became unreliable due to the propagation of cracks in the extreme fibers in tension. The stresses in the compression part of the section however, demonstrated the specific stress pattern as a function of the nodal distance to the neutral axes.

\section{CONCLUSION}

The failure criteria as proposed by Möhr-Coulomb and Kupfer-Hilsdorf-Rusch were evaluated by the developed FEM program. It was shown that for conventional concretes with a cylindrical compression strength not exceeding $75 \mathrm{MPa}$, the both failure envelopes resulted in the same predicted ultimate load carrying capacity.

For compression strengths exceeding this value, the $\mathrm{KHC}$ failure criteria will predict a higher ultimate load due to the confinement effect in bi-axial compression. As shown in Fig. 1 , the substantial difference between the MC and the KHR envelope lies in this bi-axial compression stress zone. The specimen in this study is predominantly a flexure element and therefore unmistaken a tensile case. Studies on the failure initiation and crack propagation of Gauss points [8] showed that initial failure was always initiated at Gauss points in compression-tension. Any strength increase originated from the confinement effect in the bi-axial compression zone, thus would not influence the ultimate load significantly. Further, the tensile-to-compression strength ratio was measured only to be $10 \%$. Therefore, an increase in compression strength will not enhance the corresponding tensile strength significantly. However, for high-strength concretes the noticeable increase in this compression strength will substantially enlarge the borders of the failure envelope, providing the opportunity of the Gauss point in bi-axial compression to benefit from the confinement effect.

Irregularities originating from the programing algorithms could be overcome with an automatic adjusting load increment algorithm that introduces a load-coefficient as a function of the rate in decrease of the structural stiffness.

\section{REFERENCES}

[1] H. Kupfer, H. K. Hilsdorf, and H. Rusch, "Behavior of concrete under biaxial stresses," ACI J. Proc., vol. 66, no. 8, pp. 656-666, August 1969.

[2] H. Fossen, Structural Geology. Cambridge University Press, 2010, pp.69-76.

[3] F. J. Labuz and A. Zang, "Mohr-Coulomb failure criterion," J. Rock Mech. and Rock Eng., vol. 45, no. 6, 2012, pp. 975-979.

[4] CEB-FIB Task Group 8.2, "State-of-art report-Constitutive modeling of high strength/high performance concrete," International Federation for Structural Concrete, Switzerland, 2008, pp. 25-30.

[5] FIB Bulletin, "Model Code 2010-First Complete Draft, vol. 1 and 2, Federal Institute of Technology, Laussane, Switzerland, 2010, pp. 120122 .

[6] W. F. Chen and A. F. Saleeb, Constitutive Equations for Engineering Material Vol. 1: Elasticity and Modeling. John Wiley and Sons, 1982.

[7] F. J. Vecchio and M. P. Collins, "The modified compression-field theory for reinforced concrete elements subjected to shear," ACI J. Proc., vol. 83, no. 2, pp. 219-231, March-April 1986.

[8] B. R. Indriyantho and A. S. Pamungkas, "Study of rupture behavior by numerical simulation," Thesis, Civil Eng. Dept., Diponegoro Univ., Semarang, Indonesia, unpulished.

[9] A. L. Han, Sukamta, and B. R. Indriyantho, "The analysis of concrete fracture by the numerical method," Proc. 2nd Annu. Int. Conf. Arch. and Civil Eng., Singapore, 2014, pp. 116-121.

[10] M. Gencoglu and B. Mobasher, "Monotonic and cyclic flexural behavior of plain concrete beams strengthened by fabric-cement based composites," 3rd Int. Conf. Struct. Eng. Mech. and Computation, 2007, A. Zingoni (ed.), pp. 1961-1966.

[11] J. Li, L. Wang, J. Li, X. Qy, and L. Jang, "Research on flexural behavior of coarse recycled aggregate-filled plain concrete," Advanced Material Research, vol. 250-253, pp. 379-382, 2011.

[12] A. L. Han and J. Purnomo, "Finite element modeling incorporating nonlinearity of material behavior based on the FIB Model Code 2010", presented at the 1st Indonesia Structural Engineering and Material Symposium (ISEMS), Dept. Civil Eng., Parahyangan Catholic University, Bandung, Indonesia, 2011.

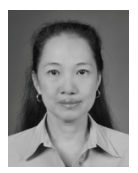

Ay Lie Han was born in Semarang, Indonesia and obtained her bachelor degree in civil engineering from the Diponegoro University, in Semarang, Indonesia. She obtained a master degree in structural engineering from the University of Manitoba, in Winnipeg, Canada and did her $\mathrm{PhD}$ in finite element micro material modeling at the Diponegoro University in Semarang, Indonesia, in collaboration with the National University of Singapore and the North Carolina State University in the USA. She is the Chair of the ACI Indonesia Chapter and a member of ASTM.

She is currently an associate professor at the Engineering Faculty, Diponegoro University in Semarang and was head of the Structural and Material Laboratory for two consecutive periods. She was visiting professor at the Micro Laboratory of the Delft University of Technology, in The Netherlands and conducted join research work with the Nihon University in Fukushima, in Japan. She is the author of numerous scientific papers in the field of finite element modeling and concrete material behavior, and is actively involved in seminars and conferences in her field of expertise.

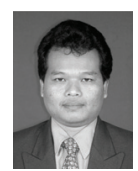

Sukamta was born in Yogyakarta, Indonesia and obtained his bachelor and master degree in structural engineering form the Gajah Mada University, in Yogyakarta, Indonesia. He pursued to a Doctorate degree with a specialization in wind engineering at the Tokushima University in Japan. 
$\mathrm{He}$ is an assistant professor in civil engineering at the Diponegoro University in Semarang, Indonesia, and a member of the structural peer group of the faculty. He is also a consultant and designer of long-span bridges, with a concentration in aero dynamics, working with major national consultants and the government. He has published many papers on the wind engineering and material behavior subject, and is actively involved in research projects conducted at the University.

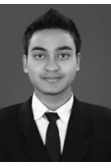

Bobby Rio Indriyantho was born in Temanggung, Indonesia. $\mathrm{He}$ is now a master student of Structural Engineering at the Diponegoro University in Semarang, Indonesia with a focus on concrete behavior. He obtained his Bachelor from the Diponegoro University.

He currently works as a structural analyst of the Material and Structural Laboratory in many projects. His research interests are concrete material behavior, finite element model, and programming. He has published some papers on the concrete behavior. 